\title{
Using Passive Smartphone Sensing for Improved Risk Stratification of Patients With Depression and Diabetes: Cross-Sectional Observational Study
}

Archana Sarda ${ }^{1}$, MBBS, MD; Suresh Munuswamy ${ }^{2}$, MBBS, MPH, PhD; Shubhankar Sarda ${ }^{3}$, BSc; Vinod Subramanian ${ }^{3}$, MBA

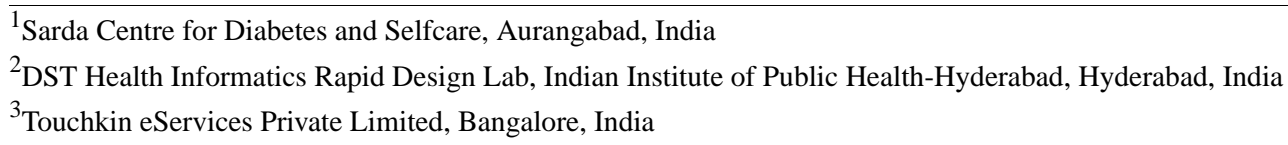

Corresponding Author:

Shubhankar Sarda, BSc

Touchkin eServices Private Limited

1st Floor, Manjusha, No 532

16th Cross, 2nd Main Road, 2nd Stage, Indira Nagar

Bangalore, 560038

India

Phone: 919762665119

Email:shubhankar@touchkin.com

\section{Abstract}

Background: Research studies are establishing the use of smartphone sensing to measure mental well-being. Smartphone sensor information captures behavioral patterns, and its analysis helps reveal well-being changes. Depression in diabetes goes highly underdiagnosed and underreported. The comorbidity has been associated with increased mortality and worse clinical outcomes, including poor glycemic control and self-management. Clinical-only intervention has been found to have a very modest effect on diabetes management among people with depression. Smartphone technologies could play a significant role in complementing comorbid care.

Objective: This study aimed to analyze the association between smartphone-sensing parameters and symptoms of depression and to explore an approach to risk-stratify people with diabetes.

Methods: A cross-sectional observational study (Project SHADO-Analyzing Social and Health Attributes through Daily Digital Observation) was conducted on 47 participants with diabetes. The study's smartphone-sensing app passively collected data regarding activity, mobility, sleep, and communication from each participant. Self-reported symptoms of depression using a validated Patient Health Questionnaire-9 (PHQ-9) were collected once every 2 weeks from all participants. A descriptive analysis was performed to understand the representation of the participants. A univariate analysis was performed on each derived sensing variable to compare behavioral changes between depression states-those with self-reported major depression (PHQ-9>9) and those with none (PHQ-9 $\leq 9)$. A classification predictive modeling, using supervised machine-learning methods, was explored using derived sensing variables as input to construct and compare classifiers that could risk-stratify people with diabetes based on symptoms of depression.

Results: A noticeably high prevalence of self-reported depression (30 out of 47 participants, 63\%) was found among the participants. Between depression states, a significant difference was found for average activity rates (daytime) between participant-day instances with symptoms of major depression (mean 16.06 [SD 14.90]) and those with none (mean 18.79 [SD 16.72]), $P=.005$. For average number of people called (calls made and received), a significant difference was found between participant-day instances with symptoms of major depression (mean 5.08 [SD 3.83]) and those with none (mean 8.59 [SD 7.05]), $P<.001$. These results suggest that participants with diabetes and symptoms of major depression exhibited lower activity through the day and maintained contact with fewer people. Using all the derived sensing variables, the extreme gradient boosting machine-learning classifier provided the best performance with an average cross-validation accuracy of 79.07\% (95\% CI 74\%-84\%) and test accuracy of $81.05 \%$ to classify symptoms of depression.

Conclusions: Participants with diabetes and self-reported symptoms of major depression were observed to show lower levels of social contact and lower activity levels during the day. Although findings must be reproduced in a broader randomized controlled 
study, this study shows promise in the use of predictive modeling for early detection of symptoms of depression in people with diabetes using smartphone-sensing information.

(JMIR Mhealth Uhealth 2019;7(1):e11041) doi: 10.2196/11041

\section{KEYWORDS}

depression; diabetes; mental health; comorbidity; passive sensing; smartphone; classification; machine learning; mHealth; risk assessment

\section{Introduction}

\section{Background}

There exists growing evidence regarding the bidirectional association between diabetes (type 2) and depression [1,2]. A meta-analysis of published studies on adults [3] reported depression to be 2 to 3 times more common in people with diabetes (both types) than in those without, with the odds of depression significantly higher in women than in men with diabetes. An estimated $8 \%$ to $35 \%$ of people across ages with diabetes mellitus (both type 1 and 2) also suffer from depression [4]. Depression increases the risk of nonadherence to medical treatment by $27 \%$ to $30 \%$ [5-7], which is a significant problem in diabetes self-care. Comorbidity (diabetes and depression) has also been associated with increased health care costs. Individuals (US adults) with diabetes who also had depression were found to be 2 to 4.5 times more expensive to treat than those with diabetes alone (US \$247 million compared with US $\$ 55$ million in 2001, dollars after adjusting for differences in age, sex, race, ethnicity, health insurance, and comorbidity) $[8,9]$. Depression is known to be associated with abnormalities in metabolism of biologics (eg, increased counterregulatory hormone release and action, changes in glucose transport function, and increased immuno-inflammatory activation) [10]. Depression might also increase the risk of developing type 2 diabetes with an increase in insulin resistance and reduction of glucose uptake in adults [11]. Comorbidity of depression and diabetes is associated with a high likelihood of complications $[12,13]$, lower quality of life [14], increased mortality [15], poor management and control [16,17], and poor disease outcomes through decreased physical activity $[18,19]$ as reported in studies covering a diverse population across age groups.

In an analysis of worldwide studies [20], it was found that primary care physicians fail to correctly diagnose between $30 \%$ and $50 \%$ of patients who present with a depressive disorder. The same study also pointed to poor recognition rates of depression symptoms among both men and women aged less than 40 years. A retrospective study [21] among a populationbased sample of primary care patients with diabetes (both type 1 and type 2, across age groups) within a US-based health maintenance organization revealed that depression is identified only half of the time (approximately 51\%). The same study also pointed that only $31 \%$ of patients with comorbid diabetes and depression received adequate antidepressant treatment and only $6.7 \%$ received 4 or more psychotherapy sessions during a 12 -month period. Clinical-only interventions seem to have very modest effects in diabetes management of patients with depression [22-24]. The American Diabetes Association recommends that patients with diabetes be screened for psychosocial and psychological problems or disorders, such as depression $[4,25]$. However, this appears to happen rarely [26].

The number of global smartphone users is expected to surpass 2.3 billion by 2017 [27]. Smartphones carry sensors such as accelerometer, global positioning system (GPS), and ambient light sensors that capture data and that could provide information on someone's behavior. In this context, the smartphone could be the most ubiquitous data collection device today. It also presents with huge privacy and security concerns. Developed nations have higher smartphone penetration, and the ownership rates in emerging and developing nations have been rising at an extraordinary rate [28]. Passive data from smartphone sensors have been known to detect patterns of behavior in people with depression [11,29-32]. Research has been establishing the link between smartphone-sensing data and its application in overall well-being [33-36] and depression [37-39]. Smartphones for social sensing [40,41], in monitoring and possibly as an intervention in mental health $[42,43]$, has the advantage of ubiquity, discretion, and low cost. Comorbidity poses a large economic burden; hence, there exists a need for effective screening and treatment. To use limited resources efficiently, risk stratification is important to target appropriate intervention for people with diabetes and depression.

\section{Previous Work}

Many studies have explored how smartphone-sensing data can be used as a predictor for depression and mental health [44-47], but very few studies have applied passive sensing to predict symptoms of depression among people with diabetes, thereby enabling improved risk stratification. There are recent studies that have attempted to predict depression among patients with diabetes using longitudinal patient records or data from clinical trials or surveys, but not using sensing data as an indicator [48-50].

\section{Study Objective}

The aim of the study was (1) to identify behaviors derived from smartphone-sensing data that are significant with symptoms of major depression compared with those with no symptoms among patients with diabetes and (2) to evaluate a risk stratification approach for early detection of symptoms of depression in patients with diabetes using smartphone-sensing parameters. To the best of our knowledge, this study was the first such implementation of using automatically captured smartphonesensing data such as activity, communication, mobility, and sleep to screen for symptoms of depression among primary care patients with diabetes. 


\section{Methods}

\section{About the Study}

The pilot study named Project SHADO (Analyzing Social and Health Attributes through Daily Digital Observation) was conducted in 2016 on a cross section of participants with diabetes located in periurban India and owning low-cost smartphones. The institutional Ethics Committee at the Public Health Foundation of India's Indian Institute of Public Health at Hyderabad, India, approved the study (Approval number IIPHH/TRCIEC/073/2016).

\section{Study Design}

The study design was conducted in association with a diabetes clinic situated in Aurangabad, a city in the state of Maharashtra, India. A cross-sectional observational study was designed to be conducted on a sample of patients undergoing diabetes treatment at the clinic. The study did not require any intervention or change in treatment or lifestyle for the participants. It did not involve a control group.

The period of the study was originally 14 weeks and later extended to 20 weeks to collect sufficient smartphone-sensing data. The study app that was used passively and anonymously collected data regarding activity, mobility, sleep, and communication from each participant. The actual conversation from the call was never collected. For identifying symptoms of depression among enrolled participants, a globally validated screening tool, Patient Health Questionnaire-9 (PHQ-9) was used [51,52]. The PHQ-9 survey was made available in both English and the local language (Marathi). The languagemodified version of PHQ-9 had been validated in other studies [53,54]. The PHQ-9 English and Marathi language questionnaire are available in Multimedia Appendices 1 and 2, respectively. For the participants to feel comfortable keeping data services enabled on their smartphones, they were provided with a $1 \mathrm{~GB}$ data recharge per month to cover for usage costs. No other incentive was provided to the participants. The care providers at the clinic administered the study. Administrator guidelines were set that ensured effective participant enrollment and onboarding process. A Web-based patient administration system was used to manage participant details. The clinical staff were oriented about the study, familiarized about the study app, and trained on the administrator system and guidelines. Effective monitoring and support was established to manage any issues that could occur during the study. The conceptual framework of the research design is shown in Multimedia Appendix 3. The study was designed to have no financial burden on the participant, nor any drug or device hazard.

\section{Study Participants}

A list of 100 periurban patients undergoing treatment for diabetes and who satisfied the study inclusion criteria (see Textbox 1) were contacted for their interest and participation in the study. Patients who did not meet the inclusion criteria, who had mobility restrictions, who were bedridden, or who had serious comorbid conditions including disabilities and visual or hearing impairment were excluded.

Overall, 47 out of the 100 patients provided their consent and were enrolled for the study. Participation in the study was voluntary, and as per the informed consent provided, a participant could decide not to participate or could withdraw from the study at any time without having to provide any reasons or justifications. All study participants followed a formal onboarding process where they were provided with information about the study; were educated about the privacy, security, and consent process; had the study app setup; provided explicit consent; and completed the initial PHQ-9 survey. The first self-reported depression score was assessed in person at the clinic followed by collection over telephone once every 2 weeks during the study period.

\section{Study App}

The study used a smartphone-sensing app (“app”) developed by Touchkin. The app assisted family members to care for their loved ones remotely and nonintrusively and to check on their well-being. The app's machine learning (ML) platform helped detect probable well-being changes by using activity rates, communication levels, sleep patterns, and mobility information collected from the user's smartphone sensors.

\section{Data Collection}

Data were deidentified before use for research purposes.

\section{Sociodemographic Data}

The participant's sociodemographic information such as gender, marital status, occupation, age, education, and family particulars were captured at enrollment. The level of control over the existing diabetes condition for each participant was assessed by the diabetologist. The participant's level of control was assessed based on their existing condition, lifestyle, and medication adherence history. Participants were classified as having low, moderate, or high control over their condition.

\section{Passive Sensing Data}

Smartphone-sensing data were captured by the app automatically every 2 minutes and stored on-device using a read or write memory card. The app was designed to capture only hashed identifiers, and the collected data were secured and anonymized on-device before being transferred to the storage servers for an aggregate analysis. All transmissions were in encrypted form using the HTTPS secure sockets layer protocol. On the server side, these files were merged, parsed, and synchronized by Python-based postprocessing infrastructure and stored in not only SQL-based servers. The servers and the data thereof were access restricted, allowing only the engineering lead to retrieve the minimal needed data for research. The raw passive sensing data were processed and daily values derived for the sensing variables. Running of the ML models on the entire deidentified dataset was performed securely on the cloud with the research analyst getting to view only the performance results. 
Textbox 1. Study inclusion and exclusion criteria.

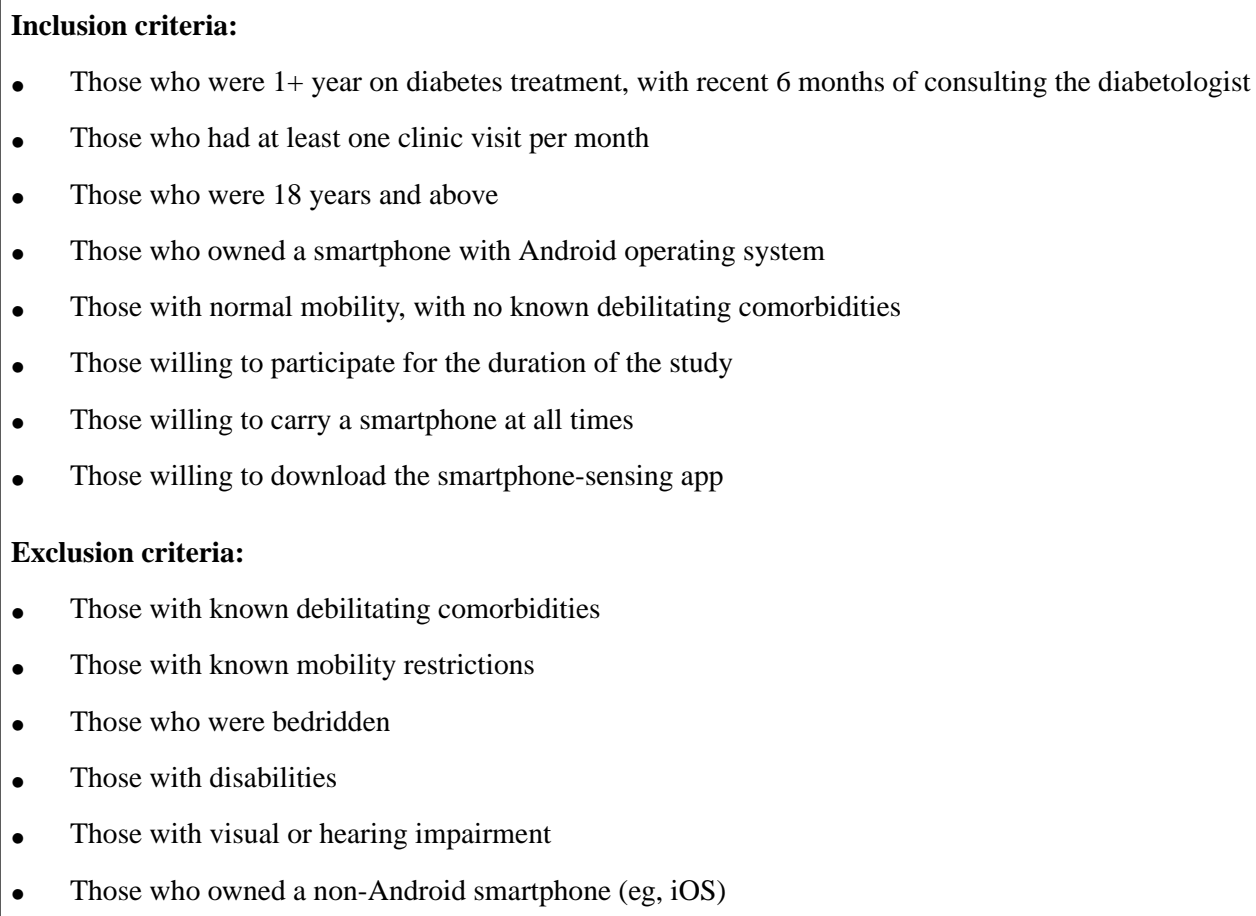

- Those who were 1+ year on diabetes treatment, with recent 6 months of consulting the diabetologist

- Those who had at least one clinic visit per month

- $\quad$ Those who were 18 years and above

- Those who owned a smartphone with Android operating system

- $\quad$ Those with normal mobility, with no known debilitating comorbidities

- Those willing to participate for the duration of the study

- Those willing to carry a smartphone at all times

- Those willing to download the smartphone-sensing app

Exclusion criteria:

- $\quad$ Those with known debilitating comorbidities

- Those with known mobility restrictions

- Those who were bedridden

- $\quad$ Those with disabilities

- Those with visual or hearing impairment

- Those who owned a non-Android smartphone (eg, iOS)

The social interaction data were captured from 3 main sensors and the call logs. These were the accelerometer, the GPS, and the ambient light sensor. All these sensors reflect pairwise communication and face-to-face proximity, intensity and nature of social ties, the dynamics of network, and amount of light in the background. To ensure that no loss of sensing data occurred in the event of network drops, they were stored in the participant's smartphone for up to 3 days.

A total of 53 sensing variables were derived from the activity, mobility, sleep, and communication data collected from the smartphone sensors. Figure 1 outlines the sensor-feature map. Activity variables were derived based on periods where the participant was found to be active. This was measured by calculating the number of times the relative gravity values, derived from accelerometer readings, exceeded the stationary threshold range (as defined from 0.8 to 1.2 ). Relative gravity is a measure of acceleration experienced by the mobile device with reference to earth's gravity. Mobility variables were derived based on the number of locations and the distance traveled (in meters). Sleep variables were based on relative gravity and the number of screen-ons. Call-related variables were based on the number of total calls (made and received), missed calls, and call duration (in minutes). Call-related variables do not include participant texting, as this was not considered in the scope of data capture. The values for these variables were derived as day-wise aggregates from the raw-sensing data collected for each participant. Details on each of the 53 derived sensing variables can be found in Multimedia Appendix 4.

Figure 1. Sensor-feature map.

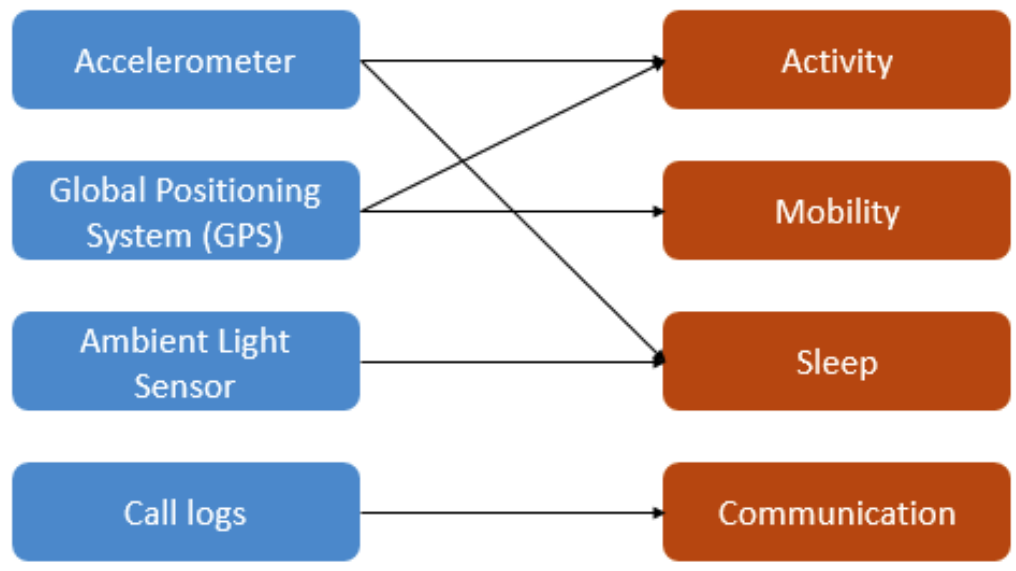




\section{Screening Instrument Data}

PHQ-9 consists of a validated 9-item depression screening tool, with each item having 4 options (scored 0-3) as responses namely: "not at all," "several days," "more than half the days," and "nearly every day." PHQ-9 helps screen for the presence and severity of depression with a maximum total score of 27. The values for each of the 53 derived sensing variables were aggregated day wise, whereas the screening data (PHQ-9 scores) were collected 14 days apart for each participant. Therefore, it was decided to impute the average of 2 consecutive PHQ-9 surveys submitted by a participant as the score for all the participant-day instances occurring between the 2 screening dates for that participant.

\section{Data Quality}

Of the 47 participants, only 1 participant did not complete the study. The final analysis was performed on data from 46 participants, of which 29 were men and 17 were women. Over the course of the study, a total of 2694 participant-day records (instances) were collected. This formed the dataset for subsequent analysis.

All PHQ-9 surveys had reminders for the participants as well as administrators to follow up. The opportunity to miss capture of sensing data could arise from many reasons, and mostly these are random in nature. Some include participants changing phone settings, forgetting to carry phones or there are errors during capture, storage, and manipulation. This resulted in dataset instances having values missing for some of the derived sensing variables. Data quality for smartphone-sensing data was an area of focus during the data gathering and data cleaning phase. Typically, low-end smartphone devices present several challenges when sending out passive sensing data, namely, frequency of data transmission varies, unexpected shutdown occurs for extended periods during the day, and data values (eg, accelerometer readings) sometimes do not match higher-end devices. Within the study, data quality measures were implemented to solve 2 issues: (1) data integrity: how to conduct reliable sampling of data to ensure there was minimum loss in continuity of data feeds and (2) data accuracy: how to ensure the validity of the data being collected, so that we could be confident that this correctly represented participant context (see Multimedia Appendix 5 for the measures taken to ensure data integrity and accuracy).

\section{Monitoring and Support}

During the study period, active support was provided to ensure minimal dropout and to ensure priority resolution of issues and monitoring of data quality. The administrators monitored the Web administration system for alerts and reached out to participants as required. Alerts included unusual smartphone usage or when 2-week surveys were due and other reasons (eg, not receiving sensing data).

\section{Smartphone Battery and Memory Optimization}

The app's technical and proprietary data collection methods ensured that the participant's smartphone battery impact was kept low. The app occupied less than $10 \mathrm{MB}$ of storage space on a typical Android smartphone and consumed less than $2 \%$ of total battery. This was lower than that consumed by other apps usually installed on a smartphone and as measured over a 24-hour period. A recent study [55] had pointed out the importance of reporting battery performance as it plays a major role in sensing data collection and quality.

\section{Data Analysis}

Analysis was performed in 3 parts: descriptive, univariate, and classification modeling.

Descriptive analysis was performed to understand the representation of the participants based on their sociodemographic factors, clinical presentations, and mental well-being.

Univariate analysis was performed to understand whether there were observable differences in behavior between a set of instances tagged with symptoms of major depression (depressed-D) and those with none (not depressed-ND). The D class included instances with PHQ-9 greater than 9 (moderate to severe severity) scores, and the ND class included instances with PHQ-9 less than or equal to 9 (none to mild severity) scores. The PHQ-9 cutoff for major depression was decided based on published studies [56]. An independent $t$ test was conducted to compare the 2 classes, considering the test's robustness with large number of instances [57]. Therefore, it was safe to assume that the data in each class were normally distributed for each derived sensing variable. It was also observed that the number of instances in the 2 classes for each derived sensing variable was significantly unbalanced. It was, therefore, decided that the unequal variance independent $t$ test [58] be applied (with and without outliers) to compare the 2 classes. It was observed that any imputation of missing values in sensing variables would potentially introduce bias, and hence no treatment was affected on the missing values.

Classification modeling was performed with the objective to explore, compare, and identify the best performing classifier method to build a risk stratification model for early detection of symptoms of depression in participants with diabetes. A total of 5 supervised ML methods and their ensemble were explored. Tree-based supervised ML methods were mostly considered, given their robustness to multicollinearity, outliers, and missing values. These include support vector machine (SVM), decision tree (DT), random forest (RF), adaptive boosting (AdaBoost), and extreme gradient boosting (XGBoost). The radial basis function (RBF) kernel used in SVM methods is known to handle large feature sets and their nonlinear interactions. The other 4 methods were tree-based methods that included the basic DT along with boosting trees (AdaBoost and XGBoost) and bagging trees (RF). Both bagging and boosting trees combine several DTs to reduce error and improve classification performance. Boosting trees help reduce bias, whereas bagging trees help reduce variance. A voting ensemble was also trained that combined each of the 5 methods to check for improved classification performance. Each of the 5 methods provides a class (D or ND) prediction (vote) for each participant-day instance, whereas the voting ensemble counts these votes and tags the majority class voted for that instance. 
Figure 2. Classification modeling (train-validate-test) approach. PHQ-9: Patient Health Questionnaire-9; SVM: support vector machine; XGBoost: extreme gradient boosting.

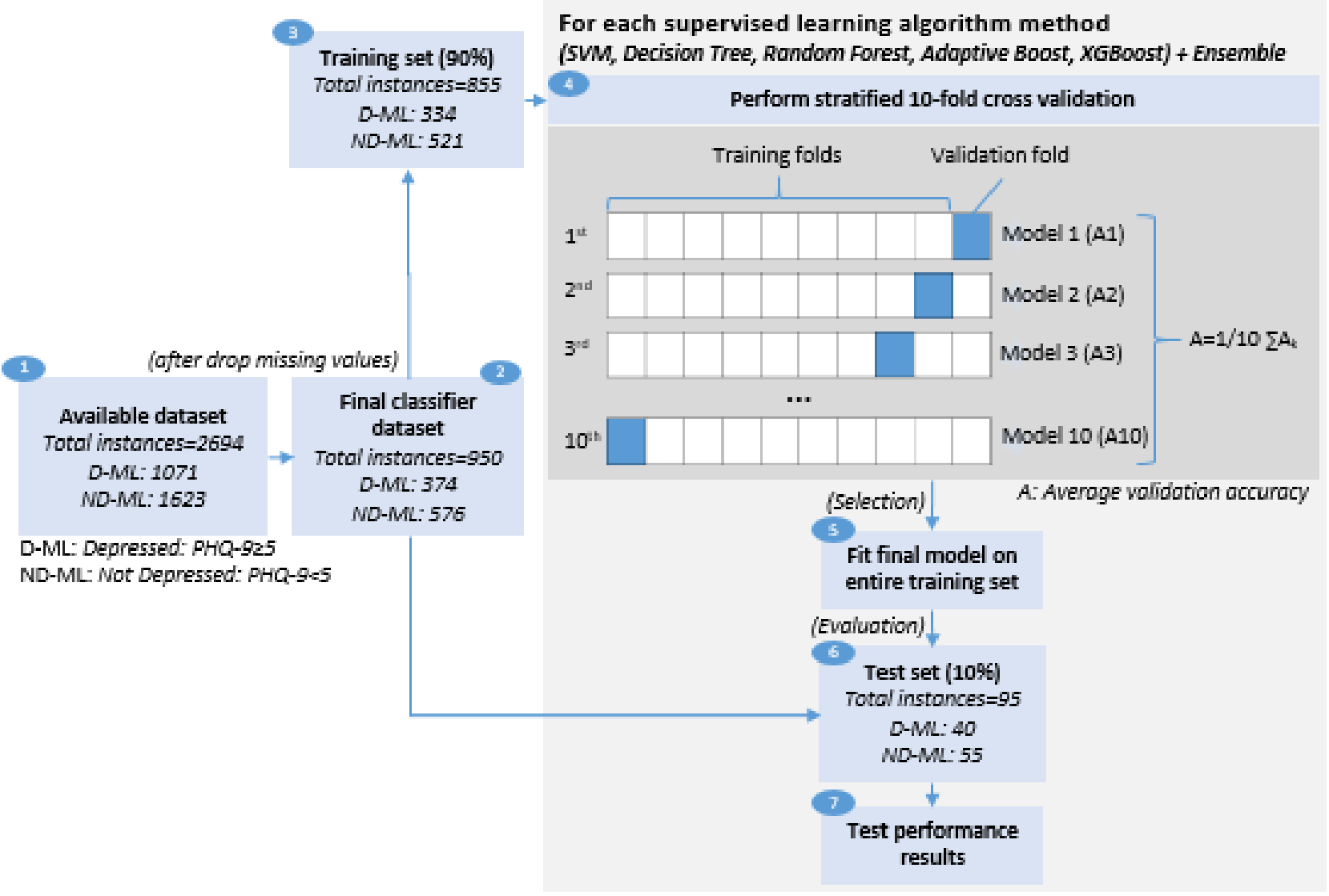

Open-source Python software on Jupyter Notebook was used for modeling. A lower PHQ-9 cutoff of 5 was considered for the modeling to broaden the scope and include instances with mild symptoms of depression.

Mild symptoms or subclinical depression in people with diabetes has been found to be common, associated with high levels of diabetes-related distress, psychological distress, and lower quality of life and also a risk indicator of major depression [59-61]. Those instances with self-reported symptoms of depression (PHQ-9 $\geq 5$ - mild to severe) were grouped under the depressed-machine learning (D-ML) class and those with none (PHQ-9<5) under the not depressed-machine learning (ND-ML) class. Instances that contained missing values in any of the 53 derived sensing variables were entirely dropped. The dataset so obtained was divided into a training set $(90 \%)$ and test set (10\%), and a stratified K-fold cross-validation (CV) with $\mathrm{K}$ equal to 10 folds was performed on the training set for each of the 5 classifier methods (see Figure 2 for the modeling approach [train-validate-test] followed). The CV has been widely used to compare different classifier methods. A major advantage of using the 10-fold CV approach is that every data instance gets to be in a validation set exactly once and gets to be in a training set 9 times, leading to lower variance in the resulting estimate. Stratification ensures that the ratio of both classes (D-ML and ND-ML) is equally represented in each fold. A CV splits the training set into $\mathrm{K}$ equal parts. A model is trained on $\mathrm{K}-1$ parts and gets validated on the remaining part. This process leads to development of $\mathrm{K}$ models for each method. The average performance of $\mathrm{K}$ models is then compared for each method. A nested CV was not opted for because of computational challenges. The final model for each method was then trained on the entire training set and tested with the unseen test set. Test performance results were then compared to identify the best ML method. Classification performance in terms of accuracy, specificity, sensitivity, and precision along with the confusion matrix was used to compare the ML methods. For this study, a lower number of false negatives (wrongly classifies symptoms of depression to be absent) was important as a wrong classification would lead to patients with symptoms of depression being missed out for priority diabetes care. Therefore, apart from high accuracy, a high recall with a reasonably high precision formed the basis to compare and select the appropriate method to build risk stratification models.

\section{Results}

\section{Descriptive Analysis}

At the start of the study, 1 out of the 47 participants had a known diagnosis for depression. A noticeably high percentage of participants (30/46), excluding 1 with a known diagnosis, self-reported symptoms of depression on the PHQ-9 survey during the study (Figure 3). Overall, 6 out of 31 reported severe symptoms of depression, including suicidal tendency. These severe cases were referred to psychologists promptly. The diabetologist ensured regular follow-up of their referred patients 
for their depression condition as per the care protocol established at the diabetes clinic.

At the beginning, 30 men and 17 women participated in the study. Of them, 1 male participant dropped out making it 29 men and 17 women at the end of study. As seen in Table 1, participants had a mean age of 35 years (SD 12). In total, 60\% $(28 / 46)$ of the participants were in the age group of 21 to 40 . Of them, 58\% (27/46) of the participants were married. A majority of the participants were office goers at $69 \%(32 / 46)$, whereas $17 \%(8 / 46)$ were students. Of them, $58 \%(27 / 46)$ of the participants held a bachelor's or master's degree, whereas $34 \%(16 / 46)$ had completed schooling. Some of the clinical characteristics of the participants included an almost equal mix of diabetes condition (type 1/type 2) and 63\% (29/46) had moderate level of control over their diabetes condition.

\section{Univariate Analysis}

All the 2694 instances (participant-day records) were included for this analysis. The results with and without outliers are summarized in Tables 2 and 3.

- A significant difference was observed in the average activity rates in the morning hours (from 6:00 am until 11:59 am) among those with symptoms of major depression (mean 13.70 [SD 14.04]) compared with those with none (mean 18.48 [SD 18.44]), $P<.001$. A significant difference was also observed in average activity rates in the remaining part of the day (from noon until 4:00 pm) among those with symptoms of major depression (mean 16.06 [SD 14.90]) than those with none (mean 18.79 [SD 16.72]), $P=.005$. These results suggested that those with symptoms of major depression exhibited lower and irregular activity rates through the day as compared with those with none.
- A significant difference was observed in the number of screen-on times at night (from midnight until 6:00 am) among those with symptoms of major depression (mean 6.70 [SD 9.33]) compared with those with none (mean 3.16 [SD 8.91]), $P<.001$. The results suggested that those with symptoms of major depression possibly had an impacted sleep quality due to higher screen-ons.

- A significant difference was observed in the average total number of calls (made and received) among those with symptoms of major depression (mean 12.61 [SD 9.15]) compared with those with none (mean 22.28 [SD 50.76]), $P<.001$. A significant difference was also observed in the average number of people called among those with symptoms of major depression (mean 5.08 [SD 3.83]) compared with those with none (mean 8.59 [SD 7.05]), $P<.001$. The results suggested that those with symptoms of major depression maintained contact with fewer people and attended fewer calls.

- Mobility variables showed limited to no statistical significance at $95 \%$ and $99 \% \mathrm{CI}$, respectively, between the 2 depression states and hence have not been reported.

Univariate trends over the weeks also showed that those with symptoms of major depression (D) exhibited irregular and lower daytime average activity rates (Figure 4 ) compared with those with none (ND).

Trends over the week showed that those with symptoms of major depression (D) had irregular and higher average number of screen-ons at nighttime (Figure 5) than those with none (ND).

Trends over the week also showed that those with symptoms of major depression (D) withdrew socially with lower average number of calls, lower average number of people contacted, and lower average duration per call (Figure 6) than those with none (ND).

Figure 3. Prevalence of depression.

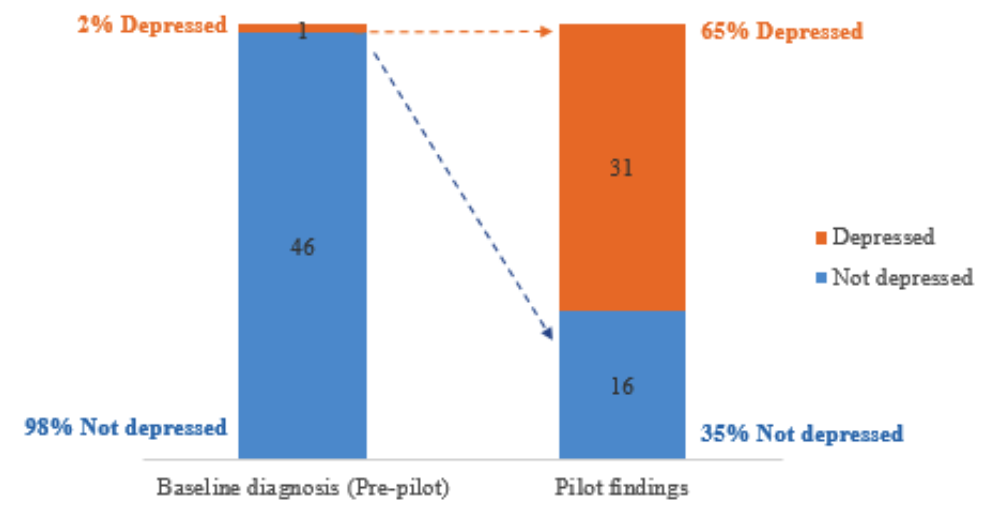


Table 1. Participant demographics $(\mathrm{N}=46)$.

\begin{tabular}{|c|c|}
\hline Participant characteristics & Statistic, n (\%) \\
\hline \multicolumn{2}{|l|}{ Age (years) } \\
\hline $15-20$ & $4(10)$ \\
\hline $21-30$ & $14(30)$ \\
\hline $31-40$ & $15(32)$ \\
\hline $41-50$ & $5(11)$ \\
\hline $51+$ & $8(17)$ \\
\hline \multicolumn{2}{|l|}{ Gender } \\
\hline Men & $29(64)$ \\
\hline Women & $17(36)$ \\
\hline \multicolumn{2}{|l|}{ Marital status } \\
\hline Single & $18(40)$ \\
\hline Married & $28(60)$ \\
\hline \multicolumn{2}{|l|}{ Education } \\
\hline Grade $10-12$ & $15(34)$ \\
\hline Bachelor's degree & $19(41)$ \\
\hline Master's degree & $9(19)$ \\
\hline Vocational education & $3(6)$ \\
\hline \multicolumn{2}{|l|}{ Occupation } \\
\hline Student & $8(17)$ \\
\hline Home & $6(13)$ \\
\hline Office & $32(70)$ \\
\hline \multicolumn{2}{|l|}{ Family } \\
\hline Living alone & $4(9)$ \\
\hline Living with family & $42(91)$ \\
\hline \multicolumn{2}{|l|}{ Chronic condition } \\
\hline Diabetes type 1 & $21(45)$ \\
\hline Diabetes type 2 & $25(55)$ \\
\hline \multicolumn{2}{|l|}{ Patient location } \\
\hline Outstation & $14(30)$ \\
\hline In city & $32(70)$ \\
\hline \multicolumn{2}{|c|}{ Level of control over diabetes condition } \\
\hline Low & $11(23)$ \\
\hline High & $7(15)$ \\
\hline Moderate & $28(62)$ \\
\hline
\end{tabular}


Table 2. Univariate analysis results (with outliers).

\begin{tabular}{|c|c|c|c|c|c|}
\hline \multirow[t]{2}{*}{ Key smartphone-sensing variables } & \multicolumn{2}{|c|}{ Depressed (PHQ-9ª $>9)$} & \multicolumn{2}{|c|}{ Not depressed (PHQ-9 $\leq 9)$} & \multirow[t]{2}{*}{$P$ value (with unequal variance) } \\
\hline & $\mathrm{n} 1^{\mathrm{b}}(\%)$ & Mean (SD) & $\mathrm{n} 2^{\mathrm{c}}(\%)$ & Mean (SD) & \\
\hline Activity rate $\left(\mathrm{am}^{\mathrm{e}}\right)$ & $194(11)$ & $13.70(14.04)$ & $1598(89)$ & $18.48(18.44)$ & $<.001$ \\
\hline Activity rate (day $\left.{ }^{f}\right)$ & $228(12)$ & $16.06(14.91)$ & $1761(88)$ & $18.79(16.72)$ & .005 \\
\hline Screen-on ${ }^{\mathrm{g}}\left(\right.$ night $\left.^{\mathrm{h}}\right)$ & $130(9)$ & $6.70(9.33)$ & 1301(91) & $3.16(8.91)$ & $<.001$ \\
\hline Calls (made and received) & $262(11)$ & $12.61(9.15)$ & 2057 (89) & $22.28(50.76)$ & $<.001$ \\
\hline People called & $262(11)$ & $5.08(3.83)$ & 2057 (89) & $8.59(7.05)$ & $<.001$ \\
\hline Call duration (minutes) & $262(11)$ & $18.95(19.32)$ & $2057(89)$ & $37.59(174.88)$ & $<.001$ \\
\hline
\end{tabular}

${ }^{\mathrm{a}} \mathrm{PHQ}$ : Patient Health Questionnaire.

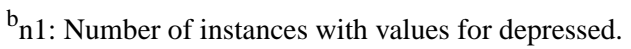

$c_{n 2}$ : Number of instances with values for not depressed.

${ }^{\mathrm{d}}$ Total number of active polled every $2 \mathrm{~min}$. Active: where relative gravity values exceed the stationary threshold range (0.8-1.2).

${ }^{\mathrm{e}}$ From 6:00 am until 11:59 am.

${ }^{\mathrm{f}}$ From noon until 4:00 pm.

${ }^{g}$ Total number of Screen-on polled every $2 \mathrm{~min}$. Screen on: where the user had their mobile screen switched on and unlocked.

${ }^{\mathrm{h}}$ From midnight until 6:00 am.

Table 3. Univariate analysis results (without outliers).

\begin{tabular}{|c|c|c|c|c|c|}
\hline \multirow[t]{2}{*}{ Key smartphone-sensing variables } & \multicolumn{2}{|c|}{ Depressed (PHQ $\left.{ }^{\mathrm{a}}-9>9\right)$} & \multicolumn{2}{|c|}{ Not depressed (PHQ-9 $\leq 9)$} & \multirow[t]{2}{*}{$P$ value (with unequal variance) } \\
\hline & $\mathrm{n} 1^{\mathrm{b}}(\%)$ & Mean (SD) & $\mathrm{n} 2^{\mathrm{c}}(\%)$ & Mean (SD) & \\
\hline Activity rate ${ }^{\mathrm{d}}\left(\mathrm{am}^{\mathrm{e}}\right)$ & $183(11)$ & $11.06(7.93)$ & $1507(89)$ & $14.87(10.80)$ & $<.001$ \\
\hline Activity rate $\left(\right.$ day $\left.^{\mathrm{f}}\right)$ & $214(11)$ & $12.95(6.96)$ & $1754(89)$ & $18.61(16.49)$ & $<.001$ \\
\hline Screen-on ${ }^{\mathrm{g}}\left(\right.$ night $\left.^{\mathrm{h}}\right)$ & $120(9)$ & $4.58(5.54)$ & $1156(91)$ & $1.32(1.69)$ & $<.001$ \\
\hline Calls (made and received) & $254(12)$ & $11.69(7.58)$ & $1933(88)$ & $16.02(11.54)$ & $<.001$ \\
\hline People called & $240(11)$ & $4.22(2.37)$ & 1965 (89) & $7.59(5.34)$ & $<.001$ \\
\hline Call duration (minutes) & $246(11)$ & $15.24(12.52)$ & $1917(89)$ & $21.36(19.21)$ & $<.001$ \\
\hline
\end{tabular}

${ }^{\mathrm{a} P H Q}$ : Patient Health Questionnaire.

$b_{n 1:}$ Number of instances with values for depressed.

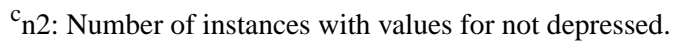

${ }^{\mathrm{d}}$ Total number of active polled every $2 \mathrm{~min}$. Active: where relative gravity values exceed the stationary threshold range (0.8-1.2).

${ }^{\mathrm{e}}$ From 6:00 am until 11:59 am.

${ }^{\mathrm{f}}$ From noon until 4:00 pm.

${ }^{\mathrm{g}}$ Total number of Screen-on polled every $2 \mathrm{~min}$. Screen on: where the user had their mobile screen switched on and unlocked.

${ }^{\mathrm{h}}$ From midnight until 6:00 am. 
Figure 4. Week-wise trend of average activity rates (day). D: depressed; ND: not depressed.

\section{Trend of average activity rates (day)}

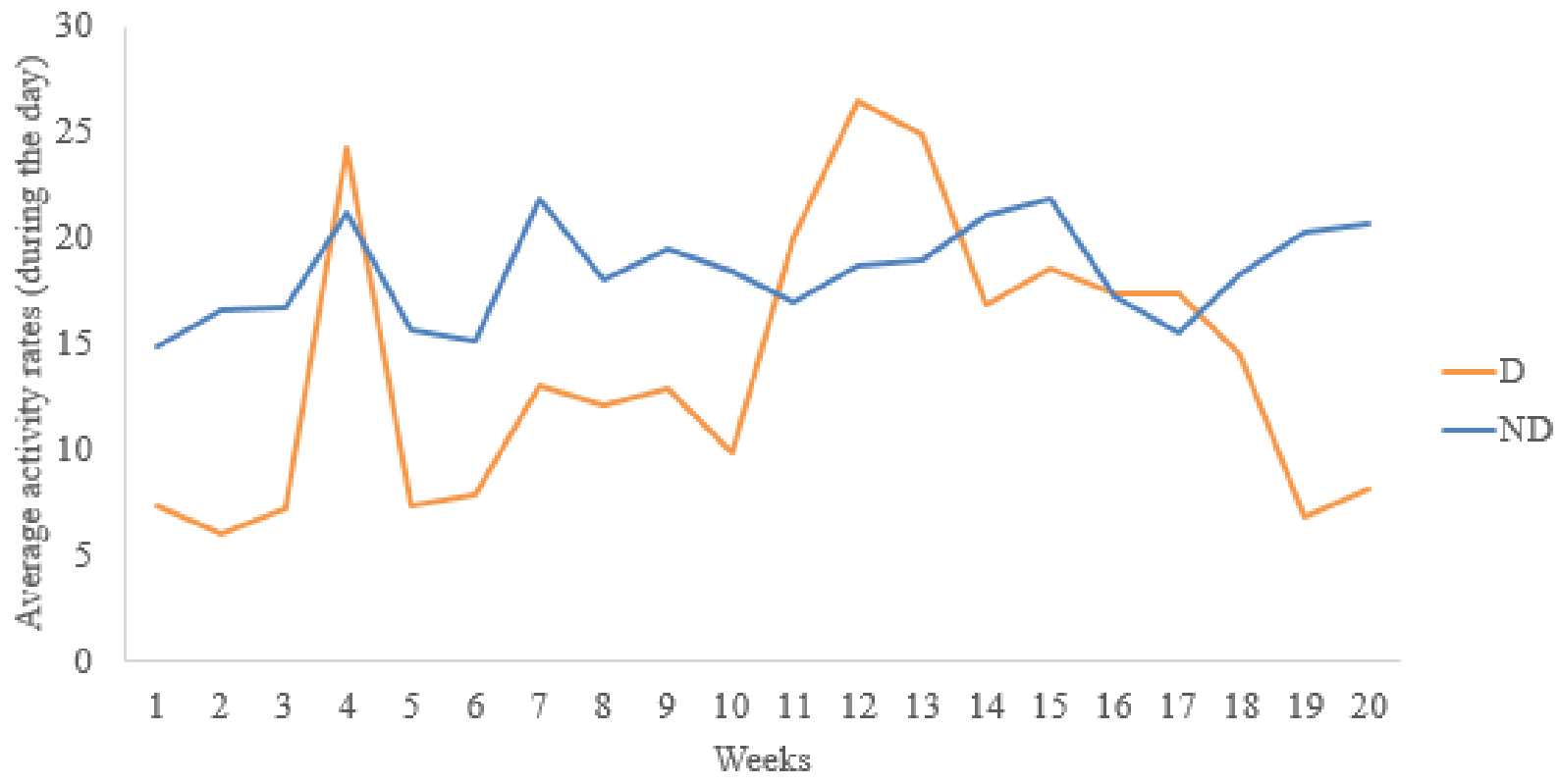

Figure 5. Week-wise trend of average screen-ons (night). D: depressed; ND: not depressed.

\section{Trend of average number of screen-ons (night)}

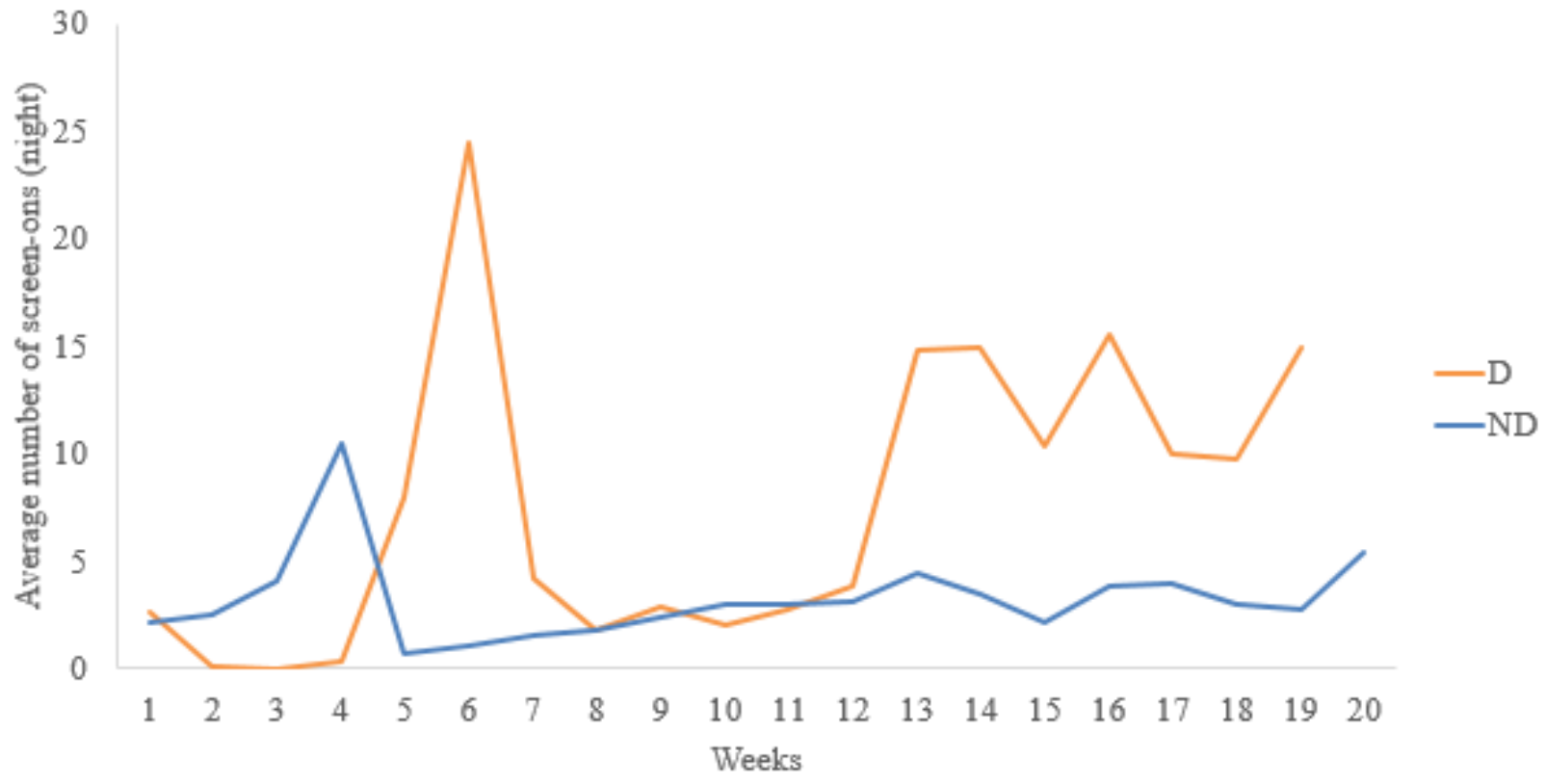


Figure 6. Week-wise trends of average calls-people-duration. D: depressed; ND: not depressed.
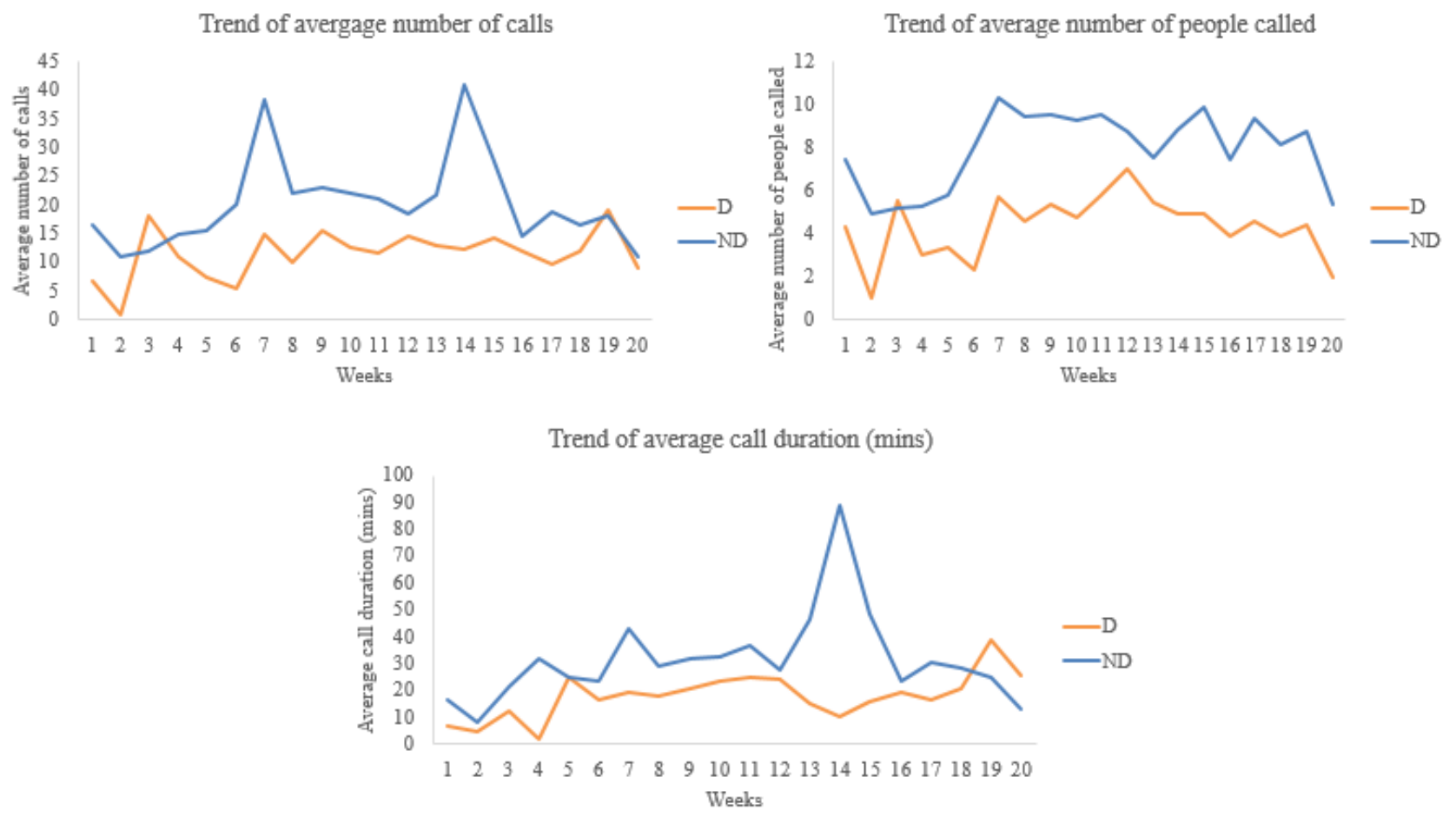

\section{Classification Analysis}

All participant-day instances with missing values in 1 or more of the 53 derived sensing variables were removed, which resulted in 950 out of 2694 instances available for analysis. A 90:10 (training:test) split resulted in 855 instances in the training set and 95 instances in the test set. A stratified 10-fold CV was performed on this training set before testing on an unseen test set.

\section{Collinearity Check}

Very low correlation ( $r$ values ranging from -.15 to .13) was observed between the self-reported depression state (PHQ-9 cutoff 5) and each of the 53 derived sensing variables as measured by Pearson correlation. High pair-wise correlation or collinearity (>80\%) was observed among some of the derived sensing variables (Multimedia Appendix 6). Mobility and communication-based variables showed higher collinearity. This was primarily due to the association between the variables and their subset, for example, "total calls at peak" and "total calls at off-peak" variables were subsets of the "total calls" variable. Activity and sleep-based variables showed lower collinearity. This was again due to the association between variables such as "total activity rates," "screen-on times," and their "time of day" subsets. For example, "total activity by day/night/eve/am" were all subsets of the "total activity" variable. As each derived sensing variable, of its own, provided rich behavioral context, it was decided to retain all the 53 variables and their subsets as inputs into the modeling.

\section{Model Development}

In total, $5 \mathrm{ML}$ methods (SVM, DT, RF, AdaBoost, and XGBoost) and their ensemble were trained and compared for performance. Accuracy provided the fraction of correctly classified samples of both classes (D-ML and ND-ML). XGBoost and RF performed the best in terms of accuracy. They reported an average cross-validated accuracy of $79.1 \%(95 \%$ CI $74 \%$ to $84 \%$ ) and $78.3 \%$ (95\% CI, $71 \%$ to $85 \%$ ), respectively, and a higher test accuracy of $81.1 \%$ and $80.0 \%$, respectively (see Table 4). Both the methods also reported a higher recall of $75.0 \%$ and $70.0 \%$, respectively, and a reasonable precision of $78.9 \%$ and $80.0 \%$, respectively, as compared with other methods. Recall can be interpreted as "Of the participant-day instances that were actually symptoms of depression, what proportion was classified as having symptoms of depression." Precision can be interpreted as "Of the participant-day instances that were classified as symptoms of depression, what proportion actually had symptoms of depression." 
Table 4. Classification performance.

\begin{tabular}{|c|c|c|c|c|c|c|}
\hline Performance & $\begin{array}{l}\mathrm{SVM}^{\mathrm{a}} \\
\left(\mathrm{RBF}^{\mathrm{b}}\right)\end{array}$ & $\begin{array}{l}\text { Decision tree } \\
\text { - single }\end{array}$ & $\begin{array}{l}\text { Random for- } \\
\text { est }\end{array}$ & $\begin{array}{l}\text { Extreme gradi- } \\
\text { ent boosting }\end{array}$ & $\begin{array}{l}\text { Adaptive } \\
\text { boost }\end{array}$ & $\begin{array}{l}\text { Voting en- } \\
\text { semble }\end{array}$ \\
\hline \multicolumn{7}{|l|}{ Accuracy } \\
\hline Average cross-validation accuracy, $\%(95 \% \mathrm{CI})$ & $73.8(67-81)$ & $69.1(60-78)$ & $78.3(71-85)$ & $79.1(74-84)$ & $74.3(67-81)$ & $75.3(68-82)$ \\
\hline Test accuracy, $\%$ & 80.0 & 66.3 & 80.0 & 81.1 & 73.7 & 77.9 \\
\hline Precision (test), $\%$ & 86.2 & 60.5 & 80.0 & 78.9 & 75.9 & 80.6 \\
\hline Sensitivity and recall (test), $\%$ & 62.5 & 57.5 & 70.0 & 75.0 & 55.0 & 62.5 \\
\hline Specificity (test), $\%$ & 92.7 & 72.7 & 87.3 & 85.5 & 87.3 & 89.1 \\
\hline \multicolumn{7}{|l|}{ Confusion matrix: training counts } \\
\hline True positive & 228 & 304 & 324 & 330 & 241 & 321 \\
\hline True negative & 487 & 503 & 521 & 520 & 485 & 519 \\
\hline False positive & 34 & 18 & 0 & 1 & 36 & 2 \\
\hline False negative & 106 & 30 & 10 & 4 & 93 & 13 \\
\hline \multicolumn{7}{|l|}{ Confusion matrix: test counts } \\
\hline True positive & 25 & 23 & 28 & 30 & 22 & 25 \\
\hline True negative & 51 & 40 & 48 & 47 & 48 & 49 \\
\hline False positive & 4 & 15 & 7 & 8 & 7 & 6 \\
\hline False negative & 15 & 17 & 12 & 10 & 18 & 15 \\
\hline
\end{tabular}

${ }^{\mathrm{a}} \mathrm{SVM}$ : support vector machine.

${ }^{\mathrm{b}} \mathrm{RBF}$ : radial basis function.

\section{Discussion}

\section{Principal Findings}

A noticeably high prevalence of self-reported symptoms of depression $(63 \%)$ was observed in this study as compared with the $8 \%$ to $35 \%$ normally reported in other studies [4]. This could be attributable to the single study site and the characteristics of the recruited participants. A detailed analysis was not within the scope of study.

Low correlation was observed between self-reported symptoms of depression and each of the derived sensing variables. This contrasts from the results observed in the Dartmouth Student Life study [41] where results indicated a strong correlation between automatic sensing data (derived for sleep, conversation, and location) and PHQ-9 scores. The difference can be attributed to the use of different sets of derived sensing variables and possibly due to missing values in the sensing variables. Again, a detailed analysis on correlation was not within the scope of study. The study did show, at $95 \%$ and $99 \%$ significance, lower levels of social contact (total calls_-made and received), higher phone access at night (number of screen-ons), and lower daytime activity (activity rates during the day) among those with self-reported symptoms of depression (PHQ-9>9).

In total, 1744 out of 2694 participant-day instances were removed from the dataset as they contained missing values in 1 or more of the derived sensing variables. Between large numbers of training instances available for modeling and avoidance of any bias being introduced in the dataset because of imputation of missing values in the derived sensing variables, a decision was taken in favor of the latter. The XGBoost and RF methods were able to classify each participant-day instance with a test accuracy of $81.1 \%$ and $80.0 \%$, respectively, and with a sensitivity and recall of $75.0 \%$ and $70.0 \%$, respectively. From among the recently published passive sensing studies, only 1 study [38] was found comparable with the approach followed in our study. In that, they used a smartphone app to collect sensing data, used a PHQ-9 self-report scale but with a cutoff of 11 to separate participants into 2 classes, and also built binary classifiers with a leave-one-out $\mathrm{CV}$ approach to predict symptoms of depression. That study used 2 classification methods, namely RF and SVM, which resulted in an accuracy of $61 \%$ and $59 \%$, respectively, and a sensitivity and recall of $62 \%$ and $72 \%$, respectively. Although the results obtained from the Project SHADO study did show better performance, it would not be appropriate to make a direct comparison given the different study design adopted by both papers. However, both studies did show a performance superior to a random classification. The classifier results show promise and points to a need to develop high-performing ML models, including evaluation of unsupervised learning approaches as ML and smartphone-sensing technologies advance. A high classifier performance allows for an early and improved detection of symptoms of depression among patients with diabetes. This enables the primary care physician to use the results of the classifier as one of the several biomarkers for high-risk classification and prioritization of patients with diabetes and provide for personalized and empathetic care. 


\section{Limitations}

Key limitations of the study included a single study site, small participant size, and the nonrandomized-based approach. The average of 2 consecutive PHQ-9 scores reported by a participant was assumed to be the depression symptom of the participant for the days and instances between the 2 screening time points. This could induce an error in outcome on days or instances where a participant was to exhibit a different mood or symptom. There is a need to investigate a better approach to capture daily symptoms of depression for each participant instead of the imputation approach taken for this study. PHQ-9, although a validated scale to screen for symptoms of depression, is not a tool to firmly diagnose depression [62]. Therefore, participants with high PHQ-9 scores need not necessarily have depression and vice versa. The study was also limited by missing values in derived sensing variables. The study design should include a plan for specific follow-up with participants, without influencing the participants, to help reduce possibilities of missing values in sensing information that might be introduced due to the participant's smartphone usage behavior. Although several measures to monitor and ensure data quality were used, limitations do exist in the data collection methods. Data collection methods can be improved further to manage the variability of mobile devices and how they respond to the data collection code set. The approach and observations from this pilot study are at best preliminary and a larger, randomized control-based study would help in validation of the findings.

\section{Conclusions}

Smartphone sensor-enabled daily digital observation of health and social attributes is a promising new approach with significant potential for management of comorbid conditions. Although the findings need to be replicated with a larger multisite randomized control study, this observational study has opened up the possibility of understanding the real-world everyday mental well-being and social attributes of people with diabetes in a clinical setting. Supplementing the smartphonesensing data with clinical records from each visit along with daily behavioral information aggregated from a smartphone-based conversational chatbot app [63] would help further the risk stratification objectives. It is equally important to be sensitive and treat passive sensing data as sensitive health information and ensure adequate privacy and security controls are in place before wider use.

\section{Acknowledgments}

Touchkin funded the pilot study and the publication fees for the study. Touchkin provided access to their smartphone app product along with technical support during the study period. Participant recruitment and study administration were managed by clinical staff and administrators at Sarda Centre for Diabetes and Selfcare. The study acknowledges the following for their support during the study: Dr Banshi Saboo, MD, FIACM, FICN, FACE, MNAMS, a diabetologist associated with Dia Care \& Hormone Clinic, Diabetology, Ahmedabad, India; Dr Girija Chetty, Associate Professor, PhD, associated with the University of Canberra, Computer Science, Canberra, Australia; Stephen Raj and Priyadarsini Suresh, associated with Public Health Foundation of India-Indian Institute of Public Health, Health Informatics, Hyderabad, India. The study acknowledges Soundarya Murthy, content editor at Touchkin, for her paper reviews and Himanshu Panwar, artificial intelligence engineer at Touchkin, along with Bindhya Rajendran and Aayush Agarwal, analytics interns at Touchkin, for their support in building and validating the machine learning methods.

\section{Authors' Contributions}

Study concept and design was provided by AS with support from SM. Ethics committee approval for the study was provided by SM. Study administration was provided by AS, SS, and the staff at diabetes clinic. Data collection, secure storage, and data aggregation were managed by SS. Research and data analysis were done by VS, SM, and SS. VS helped in drafting the paper. Data interpretation was done by all authors. The paper was reviewed by all authors.

\section{Conflicts of Interest}

AS (first author) is also an advisor to Touchkin and without any fiduciary relation. SM (second author) is a program coordinator with Public Health Foundation of India and holds no conflict of interest. SS (third author) is an engineering lead and a paid employee of Touchkin. VS (fourth author) is an independent research consultant at Touchkin and draws a consulting fee.

\section{Multimedia Appendix 1}

Patient Health Questionnaire- 9 English language version.

[PDF File (Adobe PDF File), 39KB-Multimedia Appendix 1]

\section{Multimedia Appendix 2}

Patient Health Questionnaire- 9 Marathi language version.

[PDF File (Adobe PDF File), 109KB-Multimedia Appendix 2]

\section{Multimedia Appendix 3}

Conceptual framework of study research design. 
[PNG File, 20KB-Multimedia Appendix 3]

\section{Multimedia Appendix 4}

Derived smartphone-sensing variable description.

[PDF File (Adobe PDF File), 68KB-Multimedia Appendix 4]

\section{Multimedia Appendix 5}

Measures taken to ensure sensing data integrity and accuracy.

[PDF File (Adobe PDF File), 23KB-Multimedia Appendix 5]

\section{Multimedia Appendix 6}

Pearson correlation of derived sensing variables and depression state.

[PNG File, 163KB-Multimedia Appendix 6]

\section{References}

1. Golden SH, Lazo M, Carnethon M, Bertoni AG, Schreiner PJ, Diez Roux AV, et al. Examining a bidirectional association between depressive symptoms and diabetes. J Am Med Assoc 2008 Jun 18;299(23):2751-2759 [FREE Full text] [doi: 10.1001/jama.299.23.2751] [Medline: 18560002]

2. Nouwen A, Winkley K, Twisk J, Lloyd CE, Peyrot M, Ismail K, European Depression in Diabetes (EDID) Research Consortium. Type 2 diabetes mellitus as a risk factor for the onset of depression: a systematic review and meta-analysis. Diabetologia 2010 Dec;53(12):2480-2486 [FREE Full text] [doi: 10.1007/s00125-010-1874-x] [Medline: 20711716]

3. Anderson RJ, Freedland KE, Clouse RE, Lustman PJ. The prevalence of comorbid depression in adults with diabetes: a meta-analysis. Diabetes Care 2001 Jun;24(6):1069-1078 [FREE Full text] [Medline: 11375373]

4. Andreoulakis E, Hyphantis T, Kandylis D, Iacovides A. Depression in diabetes mellitus: a comprehensive review. Hippokratia 2012 Jul;16(3):205-214 [FREE Full text] [Medline: 23935284]

5. Martin LR, Williams SL, Haskard KB, Dimatteo MR. The challenge of patient adherence. Ther Clin Risk Manag 2005 Sep;1(3):189-199 [FREE Full text] [Medline: 18360559]

6. Gonzalez JS, Peyrot M, McCarl LA, Collins EM, Serpa L, Mimiaga MJ, et al. Depression and diabetes treatment nonadherence: a meta-analysis. Diabetes Care 2008 Dec;31(12):2398-2403 [FREE Full text] [doi: 10.2337/dc08-1341] [Medline: 19033420 ]

7. Dirmaier J, Watzke B, Koch U, Schulz H, Lehnert H, Pieper L, et al. Diabetes in primary care: prospective associations between depression, nonadherence and glycemic control. Psychother Psychosom 2010;79(3):172-178. [doi: 10.1159/000296135] [Medline: 20234147]

8. Chapman DP, Perry GS, Strine TW. The vital link between chronic disease and depressive disorders. Prev Chronic Dis 2005 Jan;2(1):A14 [FREE Full text] [Medline: 15670467]

9. Egede LE, Walker RJ, Bishu K, Dismuke CE. Trends in costs of depression in adults with diabetes in the United States: Medical Expenditure Panel Survey, 2004-2011. J Gen Intern Med 2016 Jun;31(6):615-622. [doi: 10.1007/s11606-016-3650-1] [Medline: 26969312]

10. Musselman DL, Betan E, Larsen H, Phillips LS. Relationship of depression to diabetes types 1 and 2: epidemiology, biology, and treatment. Biol Psychiatry 2003 Aug 01;54(3):317-329. [Medline: 12893107]

11. Talbot F, Nouwen A. A review of the relationship between depression and diabetes in adults: is there a link? Diabetes Care 2000 Oct;23(10):1556-1562. [Medline: 11023152]

12. Aguilera A, Lyles CR. The case for jointly targeting diabetes and depression among vulnerable patients using digital technology. JMIR Diabetes 2017 Jan 17;2(1):e1 [FREE Full text] [doi: 10.2196/diabetes.6916] [Medline: 30291080]

13. Colon E, Giachello A, McIver L, Pacheco G, Vela L. Diabetes and depression in the Hispanic/Latino community. Clin Diabetes 2013 Jan 17;31(1):43-45. [doi: 10.2337/diaclin.31.1.43]

14. Schram MT, Baan CA, Pouwer F. Depression and quality of life in patients with diabetes: a systematic review from the European Depression in Diabetes (EDID) Research Consortium. Curr Diabetes Rev 2009 May;5(2):112-119 [FREE Full text] [Medline: 19442096]

15. Katon WJ, Rutter C, Simon G, Lin EH, Ludman E, Ciechanowski P, et al. The association of comorbid depression with mortality in patients with type 2 diabetes. Diabetes Care 2005 Nov;28(11):2668-2672 [FREE Full text] [Medline: 16249537]

16. Lustman PJ, Clouse RE. Depression in diabetic patients: the relationship between mood and glycemic control. J Diabetes Complications 2005;19(2):113-122. [doi: 10.1016/j.jdiacomp.2004.01.002] [Medline: 15745842]

17. McKellar JD, Humphreys K, Piette JD. Depression increases diabetes symptoms by complicating patients' self-care adherence. Diabetes Educ 2004;30(3):485-492. [doi: 10.1177/014572170403000320] [Medline: 15208846] 
18. Koopmans B, Pouwer F, de Bie RA, van Rooij ES, Leusink GL, Pop VJ. Depressive symptoms are associated with physical inactivity in patients with type 2 diabetes. The DIAZOB Primary Care Diabetes study. Fam Pract 2009 Jun;26(3):171-173. [doi: 10.1093/fampra/cmp016] [Medline: 19321598]

19. von Korff M, Katon W, Lin EH, Simon G, Ludman E, Oliver M, et al. Potentially modifiable factors associated with disability among people with diabetes. Psychosom Med 2005;67(2):233-240. [doi: 10.1097/01.psy.0000155662.82621.50] [Medline: 15784788]

20. Wittchen H, Mühlig S, Beesdo K. Mental disorders in primary care. Dialogues Clin Neurosci 2003 Jun;5(2):115-128 [FREE Full text] [Medline: 22034245]

21. Katon WJ, Simon G, Russo J, von Korff M, Lin EH, Ludman E, et al. Quality of depression care in a population-based sample of patients with diabetes and major depression. Med Care 2004 Dec;42(12):1222-1229. [Medline: 15550802]

22. Cherrington A, Ayala GX, Sleath B, Corbie-Smith G. Examining knowledge, attitudes, and beliefs about depression among Latino adults with type 2 diabetes. Diabetes Educ 2006;32(4):603-613. [doi: 10.1177/0145721706290836] [Medline: 16873598]

23. Rubin RR, Knowler WC, Ma Y, Marrero DG, Edelstein SL, Walker EA, Diabetes Prevention Program Research Group. Depression symptoms and antidepressant medicine use in Diabetes Prevention Program participants. Diabetes Care 2005 Apr;28(4):830-837 [FREE Full text] [Medline: 15793181]

24. Rubin RR, Ciechanowski P, Egede LE, Lin EH, Lustman PJ. Recognizing and treating depression in patients with diabetes. Curr Diab Rep 2004 Apr;4(2):119-125. [Medline: 15035972]

25. American Diabetes Association. Standards of medical care in diabetes-2015 abridged for primary care providers. Clin Diabetes 2015 Apr;33(2):97-111 [FREE Full text] [doi: 10.2337/diaclin.33.2.97] [Medline: 25897193]

26. Akincigil A, Matthews EB. National rates and patterns of depression screening in primary care: results from 2012 and 2013. Psychiatr Serv 2017 Jul 01;68(7):660-666. [doi: 10.1176/appi.ps.201600096] [Medline: 28196461]

27. eMarketer. 2014 Dec 11. 2 Billion Consumers Worldwide to Get Smart(phones) by 2016 URL: https://www.emarketer.com/ Article/2-Billion-Consumers-Worldwide-Smartphones-by-2016/1011694 [accessed 2018-01-15] [WebCite Cache ID 6wTzEPULT]

28. Poushter J. Pew Research Center. 2016 Feb 22. Smartphone Ownership and Internet Usage Continues to Climb in Emerging Economies URL: http://assets.pewresearch.org/wp-content/uploads/sites/2/2016/02/ pew_research_center_global_technology_report_final_february_22_2016.pdf [accessed 2018-01-15] [WebCite Cache ID $\underline{6 w U 1 u 4 w U n]}$

29. Harari GM, Lane ND, Wang R, Crosier BS, Campbell AT, Gosling SD. Using smartphones to collect behavioral data in psychological science: opportunities, practical considerations, and challenges. Perspect Psychol Sci 2016 Nov;11(6):838-854. [doi: 10.1177/1745691616650285] [Medline: 27899727]

30. Doryab A, Min J, Wiese J, Zimmerman J, Hong J. Association for the Advancement of Artificial Intelligence. North America: AAAI Workshops; 2014 Jun. Detection of behavior change in people with depression URL: https://www.aaai.org/ ocs/index.php/WS/AAAIW14/paper/view/8850/8303 [accessed 2018-12-10] [WebCite Cache ID 74Yaewm7M]

31. Glynn LG, Hayes PS, Casey M, Glynn F, Alvarez-Iglesias A, Newell J, et al. Effectiveness of a smartphone application to promote physical activity in primary care: the SMART MOVE randomised controlled trial. Br J Gen Pract 2014 Jul;64(624):e384-e391. [doi: 10.3399/bjgp14X680461] [Medline: 24982490]

32. Canzian L, Musolesi M. Trajectories of depression: unobtrusive monitoring of depressive states by means of smartphone mobility traces analysis. In: Proceedings of the 2015 ACM International Joint Conference on Pervasive and Ubiquitous Computing. 2015 Presented at: UbiComp'15; September 07-11, 2015; Osaka, Japan p. 1293-1304. [doi: $10.1145 / 2750858.2805845]$

33. Cornet VP, Holden RJ. Systematic review of smartphone-based passive sensing for health and wellbeing. J Biomed Inform 2018 Jan;77:120-132. [doi: 10.1016/j.jbi.2017.12.008] [Medline: 29248628]

34. DeMasi O, Feygin S, Dembo A, Aguilera A, Recht B. Well-being tracking via smartphone-measured activity and sleep: cohort study. JMIR Mhealth Uhealth 2017 Oct 05;5(10):e137 [FREE Full text] [doi: 10.2196/mhealth.7820] [Medline: $\underline{28982643]}$

35. Jaques N, Taylor S, Azaria A, Ghandeharioun A, Sano A, Picard R. Predicting students' happiness from physiology, phone, mobility, and behavioral data. In: International Conference on Affective Computing and Intelligent Interaction and workshops: [proceedings]. 2015 Sep Presented at: ACII 2015; September 21-24, 2015; Xi'an, China p. 222-228 URL: http://europepmc. org/articles/PMC5431070 [doi: 10.1109/ACII.2015.7344575]

36. Rabbi M, Ali S, Choudhury T, Berke E. Passive and in-situ assessment of mental and physical well-being using mobile sensors. In: Proceedings of the 13th international conference on Ubiquitous computing. 2011 Presented at: UbiComp'11; September 17 - 21, 2011; Beijing, China p. 385-394 URL: http://europepmc.org/abstract/MED/25285324 [doi: 10.1145/2030112.2030164]

37. Place S, Blanch-Hartigan D, Rubin C, Gorrostieta C, Mead C, Kane J, et al. Behavioral indicators on a mobile sensing platform predict clinically validated psychiatric symptoms of mood and anxiety disorders. J Med Internet Res 2017 Mar 16;19(3):e75 [FREE Full text] [doi: 10.2196/jmir.6678] [Medline: 28302595] 
38. Wahle F, Kowatsch T, Fleisch E, Rufer M, Weidt S. Mobile sensing and support for people with depression: a pilot trial in the wild. JMIR Mhealth Uhealth 2016 Sep 21;4(3):e111 [FREE Full text] [doi: 10.2196/mhealth.5960] [Medline: 27655245]

39. Ben-Zeev D, Scherer EA, Wang R, Xie H, Campbell AT. Next-generation psychiatric assessment: using smartphone sensors to monitor behavior and mental health. Psychiatr Rehabil J 2015 Sep;38(3):218-226 [FREE Full text] [doi: 10.1037/prj0000130] [Medline: 25844912]

40. Madan A, Cebrian M, Lazer D, Pentland A. Social sensing for epidemiological behaviour change. In: Proceedings of the 12th ACM international conference on Ubiquitous computing. 2010 Presented at: UbiComp'10; September 26 - 29, 2010 ; Copenhagen, Denmark p. 291-300. [doi: 10.1145/1864349.1864394]

41. Wang R, Chen F, Chen Z, Li T, Harari G, Tignor S, et al. Student Life: assessing mental health, academic performance and behavioural trends of college students using smartphones. In: Proceedings of the 2014 ACM International Joint Conference on Pervasive and Ubiquitous Computing. 2014 Presented at: UbiComp'14; September 13 - 17, 2014 ; Seattle, Washington p. 3-14. [doi: 10.1145/2632048.2632054]

42. Torous J, Friedman R, Keshavan M. Smartphone ownership and interest in mobile applications to monitor symptoms of mental health conditions. JMIR Mhealth Uhealth 2014;2(1):e2 [FREE Full text] [doi: 10.2196/mhealth.2994] [Medline: 25098314]

43. Osmani V. Smartphones in mental health: detecting depressive and manic episodes. IEEE Pervasive Comput 2015;14(3):10-13. [doi: 10.1109/MPRV.2015.54]

44. Hung GC, Yang PC, Chang CC, Chiang JH, Chen YY. Predicting negative emotions based on mobile phone usage patterns: an exploratory study. JMIR Res Protoc 2016 Aug 10;5(3):e160 [FREE Full text] [doi: 10.2196/resprot.5551] [Medline: 27511748]

45. Saeb S, Lattie EG, Schueller SM, Kording KP, Mohr DC. The relationship between mobile phone location sensor data and depressive symptom severity. PeerJ 2016;4:e2537 [FREE Full text] [doi: 10.7717/peerj.2537] [Medline: 28344895]

46. Saeb S, Zhang M, Karr CJ, Schueller SM, Corden ME, Kording KP, et al. Mobile phone sensor correlates of depressive symptom severity in daily-life behavior: an exploratory study. J Med Internet Res 2015;17(7):e175 [FREE Full text] [doi: 10.2196/jmir.4273] [Medline: 26180009]

47. Saeb S, Zhang M, Kwasny MM, Karr CJ, Kording K, Mohr DC. The Relationship between Clinical, Momentary, and Sensor-based Assessment of Depression. In: Proceedings of the 9th International Conference on Pervasive Computing Technologies for Healthcare. 2015 Aug Presented at: PervasiveHealth'15; May 20-23, 2015; Istanbul, Turkey p. $229-232$ URL: http://europepmc.org/abstract/MED/26640739 [doi: 10.4108/icst.pervasivehealth.2015.259034]

48. Jin H, Wu S, Vidyanti I, di Capua P, Wu B. Predicting depression among patients with diabetes using longitudinal data. A multilevel regression model. Methods Inf Med 2015;54(6):553-559. [doi: 10.3414/ME14-02-0009] [Medline: 26577265]

49. Jin $\mathrm{H}, \mathrm{Wu} \mathrm{S}$, di Capua P. Development of a clinical forecasting model to predict comorbid depression among diabetes patients and an application in depression screening policy making. Prev Chronic Dis 2015 Sep 03;12:E142 [FREE Full text] [doi: 10.5888/pcd12.150047] [Medline: 26334714]

50. Khater D, Omar M. Frequency and risk factors of depression in type 1 diabetes in a developing country. J Pediatr Endocrinol Metab 2017 Aug 28;30(9):917-922. [doi: 10.1515/jpem-2016-0414] [Medline: 28771435]

51. Kocalevent R, Hinz A, Brähler E. Standardization of the depression screener Patient Health Questionnaire (PHQ-9) in the general population. Gen Hosp Psychiatry 2013;35(5):551-555. [doi: 10.1016/j.genhosppsych.2013.04.006] [Medline: 23664569]

52. Kroenke K, Spitzer RL, Williams JB. The PHQ-9: validity of a brief depression severity measure. J Gen Intern Med 2001 Sep;16(9):606-613 [FREE Full text] [Medline: 11556941]

53. Shidhaye R, Gangale S, Patel V. Prevalence and treatment coverage for depression: a population-based survey in Vidarbha, India. Soc Psychiatry Psychiatr Epidemiol 2016 Dec;51(7):993-1003 [FREE Full text] [doi: 10.1007/s00127-016-1220-9] [Medline: 27106852]

54. Kochhar PH, Rajadhyaksha SS, Suvarna VR. Translation and validation of brief patient health questionnaire against DSM IV as a tool to diagnose major depressive disorder in Indian patients. J Postgrad Med 2007;53(2):102-107 [REEE Full text] [Medline: 17495375$]$

55. Boonstra TW, Nicholas J, Wong QJ, Shaw F, Townsend S, Christensen H. Using mobile phone sensor technology for mental health research: integrated analysis to identify hidden challenges and potential solutions. J Med Internet Res 2018 Jul 30;20(7):e10131 [FREE Full text] [doi: 10.2196/10131] [Medline: 30061092]

56. Manea L, Gilbody S, McMillan D. Optimal cut-off score for diagnosing depression with the Patient Health Questionnaire (PHQ-9): a meta-analysis. CMAJ 2012 Feb 21;184(3):E191-E196 [FREE Full text] [doi: 10.1503/cmaj.110829] [Medline: 22184363]

57. Rochon J, Gondan M, Kieser M. To test or not to test: preliminary assessment of normality when comparing two independent samples. BMC Med Res Methodol 2012 Jun 19;12:81 [FREE Full text] [doi: 10.1186/1471-2288-12-81] [Medline: 22712852]

58. Ruxton GD. The unequal variance t-test is an underused alternative to Student's t-test and the Mann-Whitney U test. Behav Ecol 2006 Jul 01;17(4):688-690 [FREE Full text] [doi: 10.1093/beheco/ark016] 
59. Hermanns N, Kulzer B, Krichbaum M, Kubiak T, Haak T. How to screen for depression and emotional problems in patients with diabetes: comparison of screening characteristics of depression questionnaires, measurement of diabetes-specific emotional problems and standard clinical assessment. Diabetologia 2006 Mar;49(3):469-477. [doi: 10.1007/s00125-005-0094-2] [Medline: 16432706]

60. Cuijpers P, Smit F. Subthreshold depression as a risk indicator for major depressive disorder: a systematic review of prospective studies. Acta Psychiatr Scand 2004 May;109(5):325-331. [doi: 10.1111/j.1600-0447.2004.00301.x] [Medline: 15049768]

61. Hermanns N, Schmitt A, Gahr A, Herder C, Nowotny B, Roden M, et al. The effect of a Diabetes-Specific Cognitive Behavioral Treatment Program (DIAMOS) for patients with diabetes and subclinical depression: results of a randomized controlled trial. Diabetes Care 2015 Apr;38(4):551-560. [doi: 10.2337/dc14-1416] [Medline: 25605812]

62. Mitchell AJ, Yadegarfar M, Gill J, Stubbs B. Case finding and screening clinical utility of the Patient Health Questionnaire (PHQ-9 and PHQ-2) for depression in primary care: a diagnostic meta-analysis of 40 studies. BJPsych Open 2016 Mar;2(2):127-138 [FREE Full text] [doi: 10.1192/bjpo.bp.115.001685] [Medline: 27703765]

63. Inkster B, Sarda S, Subramanian V. An empathy-driven, conversational artificial intelligence agent (Wysa) for digital mental well-being: real-world data evaluation mixed-methods study. JMIR Mhealth Uhealth 2018 Nov 23;6(11):e12106 [FREE Full text] [doi: 10.2196/12106] [Medline: $\underline{30470676]}$

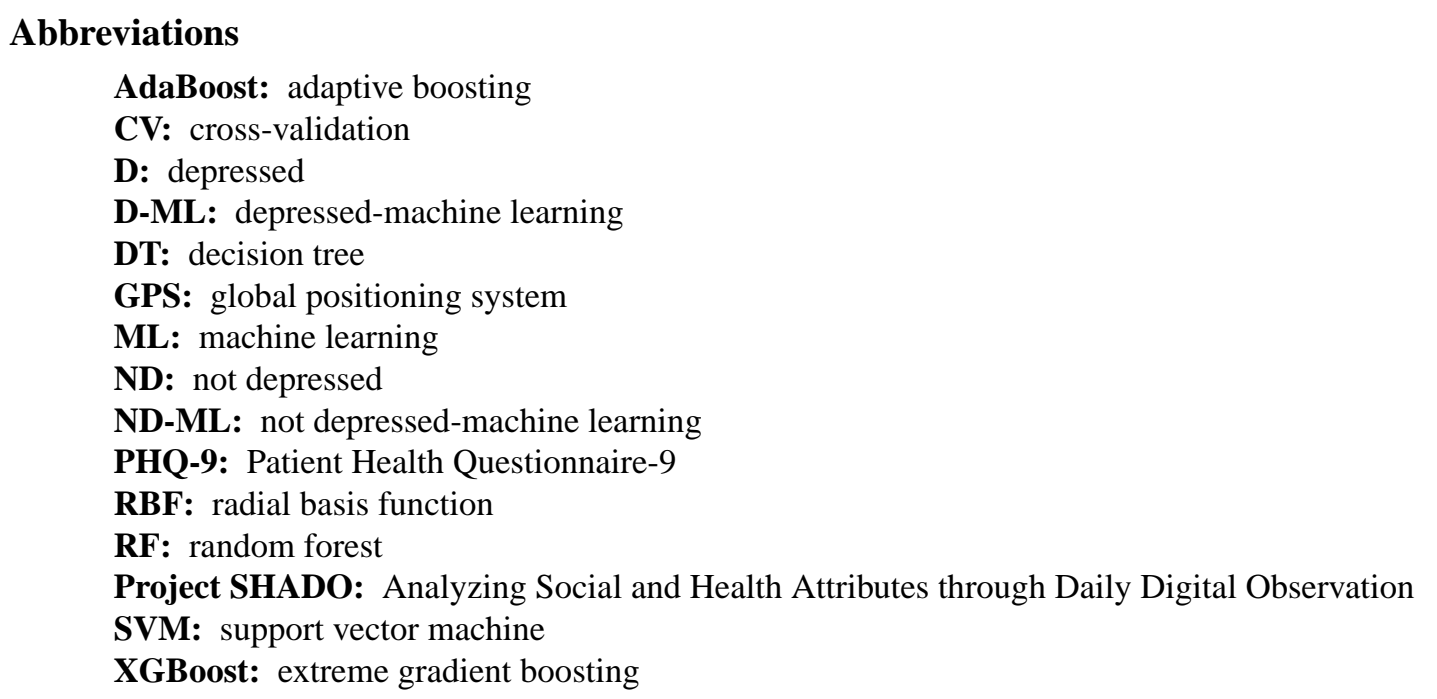

Edited by G Eysenbach; submitted 14.05.18; peer-reviewed by P Soderlund, F Fatehi, Z Huang; comments to author 24.09.18; revised
version received 19.11.18; accepted 25.11.18; published 29.01.19
Please cite as:
Sarda A, Munuswamy S, Sarda S, Subramanian V
Using Passive Smartphone Sensing for Improved Risk Stratification of Patients With Depression and Diabetes: Cross-Sectional
Observational Study
JMIR Mhealth Uhealth 2019;7(1):e11041
URL: $\underline{\text { http://mhealth.jmir.org/2019/1/e11041/ }}$
doi: $10.2196 / 11041$
PMID: $\underline{30694197}$

(C)Archana Sarda, Suresh Munuswamy, Shubhankar Sarda, Vinod Subramanian. Originally published in JMIR Mhealth and Uhealth (http://mhealth.jmir.org), 29.01.2019. This is an open-access article distributed under the terms of the Creative Commons Attribution License (https://creativecommons.org/licenses/by/4.0/), which permits unrestricted use, distribution, and reproduction in any medium, provided the original work, first published in JMIR mhealth and uhealth, is properly cited. The complete bibliographic information, a link to the original publication on http://mhealth.jmir.org/, as well as this copyright and license information must be included. 